\title{
A MORAL CONTRATUALISTA EM ERNST TUGENDHAT
}

Luiz Vicente Vieira*

SÍNTESE - O artigo tenciona estabelecer um paralelo entre a posição inicial de Tugendhat sobre a moral contratualista exposta em Lições sobre Ética, então considerada uma "moral insuficiente", e aquela assumida atualmente pelo autor, segundo a qual a moral contratualista é entendida como o "núcleo de uma moral não autoritária". Este trabalho localiza na sua reinterpretação do conceito de contrato moral a razão da mudança do autor em relação a esta corrente ética contemporânea.

PALAVRAS-CHAVE - Moral autoritária. Moral contratualista. Ética contemporânea.
ABSTRACT - This article intends to establish a parallel between Tugendhat's earlier position on morals by agreement, exposed in Lições sobre Ética, at that time considered an "insufficient ethic," and the other position currently held by the same author, according to which morals by agreement are understood as "the nucleus of a non-authoritarian ethic." This article locates Tugendhat's shift in his reinterpretation of the concept of moral contract vis à vis this contemporary trend in ethics.

KEY WORDS - Authoritarian ethic. Morals by agreement. Contemporary ethics.

O contratualismo encontra-se atualmente entre as correntes éticas mais discutidas, principalmente na sua versão chamada neo-contratualista. Autores bem conhecidos como John Rawls, D. Gauthier e Michel Walzer encontram-se, entre outros, na lista dos pensadores contemporâneos mais debatidos. A contribuição de Enst Tugendhat, em relação a esta temática, enriquece tal discussão ao estabelecer algumas críticas às visões tradicionais do contratualismo bem como ao assumir uma posição diferenciada no contexto deste debate. Ao longo dos últimos anos o autor, que se vem preocupando com esta problemática, tem procurado amadurecer uma compreensão do contratualismo enquanto sistema moral. Neste texto procuro estabelecer um confronto entre as posições assumidas pelo autor, com referência a esta questão, a partir de uma comparação entre as idéias apresentadas no seu livro Lições sobre Ética e a posição que vem atualmente defendendo. Tenciono, desta forma, após a apresentação resumida dos argumentos do autor em dois momentos distintos de sua elaboração teórica da questão Ética, localizar os pontos centrais de sua formulação onde é possível apontar-se as razões que levaram Tugendhat a modificar o seu posicionamento em relação ao

* Doutorando do Programa de Pós-Graduação em Filosofia da PUCRS. 
contratualismo, saindo de uma posição em que considerava este sistema ético como insuficiente, enquanto uma verdadeira moral, para posteriormente vir a assumi-lo como a única base efetiva para a construção de uma moral moderna.

\section{O contratualismo nas Lições sobre Ética}

A argumentação do autor em sua obra Lições sobre Ética objetiva demonstrar a dificuldade do contratualismo em legitimar-se enquanto propriamente "uma moral". Pois, segundo suas próprias palavras, trata-se, apenas, de uma "quase moral". Como ele chega a esta conclusão? O seu raciocínio parte, entre outras considerações, da observação de que, com relação aos conteúdos, resultam dois níveis de moral, fundamentada, os quais, metaforicamente, poderiam denominarse um superior e um inferior. O Inferior é o contratualismo moral, nivel este que é fortemente justificado, porém, "de pouco alcance", não satisfazendo, o "sentido previamente destacado de uma moral" (cf. Tugendhat, 97,29). Distingue o autor, ainda, entre fundamentos: que são fundamentos para a verdade de enunciados, e motivos, que são fundamentos que justificam uma ação, um modo de ação ou até mesmo a aceitação de um sistema moral. Segundo o autor, nesta obra, o contratualista não faz nenhum juízo moral, pois para ele somente existem fundamentos no sentido de motivos, enquanto que no denominado plano superior é que são feitos juízos morais onde é afirmado que algo é bom ou mau. O contratualismo, segundo o seu raciocínio, situa-se num plano ainda amoral apesar de possuir bons motivos (não obrigatórios) para ir além, assumindo também o plano da própria moral. Ou seja, o contratualismo não atinge o nível da consciência moral. E somente quem tem um senso moral pode indignar-se com outrem, podendo, deste modo, simplesmente desenvolver um comportamento instrumental para com as normas morais. O contratualismo seria, assim, próprio ao Lack of moral sense (Falta de consciência moral).

Para Tugendhat, a consciência moral resulta de um "eu quero" não motivado naturalmente. Esta suposição foi própria das éticas tradicionalistas, assim como da kantiana, que compreenderam a consciência moral "como algo fixado em nossa consciência pela natureza", idéia esta, que, no seu entender, constitui-se num resíduo teológico. Para ele somos de fato mais livres e a nossa autonomia vai bem mais longe. "O que se tem de compreender aqui, sobretudo, é que um eu tenho de não apoiado em um eu quero, sempre implícito, é encarado logicamente um absurdo (Unding)" (Tugendhat, 97,66). Esta afirmação é central para a compreensão de moral para o autor permanecendo sempre presente ao longo de toda a elaboração de sua Ética. Ele observa que a regra de ouro: comporta-te de tal maneira em relação aos outros como desejas que eles se comportem em relação a ti, pode ser compreendida como um domínio nuclear da moral, como tendo em sua base um pacto implícito. Ele acrescenta, então, que se a moral for compreendida contratualisticamente seria irracional obedecer a normas morais, a não ser em relação àqueles com os quais se está interessado em cooperar. Desaparece, segundo a sua argumentação, a pretensão de universalidade limitada que se encontra nas morais tradicionais. O autor refere-se, neste ponto, à crítica de Platão, na República, a uma concepção contratualista da moral, pois quem segue esta 
orientação comporta-se mais racionalmente quando simplesmente observa as regras morais segundo a aparência, violando-as, contudo, onde lhe for útil e puder fazê-lo sem ser identificado. No mesmo sentido refere-se a Hobbes quando este afirma que a observância das regras somente é possivel pelo Estado, ou seja, quando o direito penal substitui a moral. Em outros termos, uma moral de fundo contratualista deveria ser controlada externamente, pois não se fundaria numa consciência moral interior.

Qual a passagem que aponta para além do contratualismo como tal? Sentir vergonha, afirma o autor, significaria ter desenvolvido uma consciência e isto seria uma sanção interna. Agindo assim a pessoa seria impedida de violar as regras, não pelo interesse na cooperação como tal ou por pressão externa, mas por si mesma. Mas, interroga Tugendhat, por que alguém no contratualismo agiria assim, pois, no nível desta orientação tal atitude é irracional? "Não é possível fundamentar a partir da base contratualista a formação de uma consciência" (Tugendhat, 97,80). Esta, quando muito, tratar-se-ia de um fator complementar, consistindo, tão só, em uma conseqüência útil para o contratualista. É, no entanto, segundo o autor, impossível fundamentar uma consciência própria a partir de uma base contratualista. Porque a consciência não se deixa instrumentalizar. Tugendhat acentua, como traço característico do contratualismo, o fato de ele não comportar um conceito de "bem". Na sua opinião, este constrói-se simplesmente na base do conceito relativo de "bom para". Isto exclui a posição contratualista da classe de conceitos morais que inclui obrigatoriamente um conceito de "bem". Sendo assim, quem fala de uma moral contratualista não pode mais empregar as palavras bom e mau em seu significado gramatical absoluto e não pode, desta forma, ter nenhuma emoção moral. Neste sentido, o contratualismo é considerado uma posição minimalista, tendo condições perfeitas de se manter, mas que não pode ir muito longe. Segundo o autor, sustentar o conceito de bem e tudo que com ele implica significa uma posição mais forte do que aquela que o contratualismo pretenderia assumir. E, acrescenta, o conceito de respeito universal corresponde a esta consciência. $\mathrm{O}$ autor observa, ainda, que a primeira fórmula do imperativo categórico: age apenas segundo aquela máxima pela qual tu ao mesmo tempo possas querer que se torne uma lei universal, assemelha-se ao contratualismo. Este seria, portanto, um passo para a fórmula do imperativo categórico. É somente a sua segunda fórmula, a do respeito aos seres humanos, que se imuniza contra a instrumentalização e que, assim, iria além do contratualismo, o qual suporia um cumprimento apenas instrumental das normas morais. Tugendhat, demonstra, assim, a insuficiência da posição contratualista para a constituição de uma verdadeira ética.

\section{A opção pelo contratualismo moral}

Ao longo do Curso "Ética e Justificação", ministrado no segundo semestre de 1998, na PUCRS, o autor, entretanto, apresentará uma posição diversa daquela defendida em suas Lições sobre Ética. Como ocorre esta alteração no pensamento de E. Tugendhat? O autor parte de algumas considerações acerca de determinadas críticas que são dirigidas ao contratualismo. Reconhece que também o criti- 
cou no seu livro Lições sobre Ética, por tratar-se de uma moral que tem um bom fundamento mas que é insuficiente. Ele pensa, contudo, que é possivel demonstrar que o contratualismo não é insuficiente. Quanto à crítica de Hegel, segundo a qual o contratualismo negaria a socialidade primária dos homens, Tugendhat considera tal crítica um mal-entendido, pois o contratualismo, bem entendido, não é uma idéia histórica nem hipotética, porque não nega a realidade social normativa mas apenas põe em questão a sua justificação. As normas sociais já seriam sempre dadas. O contratualismo não começa com o indivíduo isolado. Começa com indivíduos sociais, porém exige que as normas sejam justificadas. Ou seja: elas só podem encontrar uma justificação se forem justificadas para cada um dos indivíduos, aspecto este que Tugendhat considera fundamental para uma Ética.

Uma outra crítica, levada em consideração, é a de que o âmbito do contratualismo é estreito demais. Tal crítica sugere uma pergunta: pode o contratualismo ter uma relação positiva para a consciência moral? Neste ponto o autor faz uma revisão de sua posição anteriormente defendida na obra acima citada, quando ele baseou-se na crítica de Platão, acima mencionada, de que no contratualismo a pessoa se portaria moralmente somente enquanto controlada de fora. Ou seja, que a pessoa que se entende contratualista seria alguém interiormente imoral, donde poderia deduzir-se que o contratualismo não poderia superar esta barreira. Tugendhat localiza aqui o que ele considera o problema principal do contratualismo que, nas suas palavras, seria a pergunta "o que é que faz a pessoa manter-se sob suas regras também quando os outros não me vêem?" E responde: "poder-se-ia dizer que é o sentido de culpa e a penalização com a possível indignação dos outros e, neste momento, se deve dizer algo: que é o lugar deste sentimento, e acho que se pode dizer que o temos biologicamente como capacidade, mas depende de nós o reforçarmos ou não" (grifo meu). O autor observa que se uma pessoa sente indignação pela ação de outra pessoa também irá sentir culpa se cometer uma ação que possa provocar a indignação de outros. Uma moral sempre é um sistema de possível inđignação dos outros, ou seja, uma avaliação mútua. "Julgamos uns aos outros se somos bons quando atuamos segundo as regras e mais segundo quando as infringimos. Mas do que não querermos ser depreciados, não queremos ser depreciáveis". E o autor conclui que não querer ser depreciável significa ter uma consciência moral. Somente a pessoa que tem um sentido moral pode envergonhar-se. Para Tugendhat, o interesse que tem uma pessoa de não ser depreciável pode ser caracterizado de egoísmo, porém, egoísmo num outro sentido, qual seja, o de ter satisfação em poder considerar-se apreciável moralmente. Tal interesse, em corresponder às exigências morais, existiria na moral que tem um fundamento contratualista como, aliás, ocorre em toda a moral por surgir do mecanismo de avaliação mútua que pertence a qualquer moral.

A Emst Tugendhat parece falsa a idéia que ele defendeu, em Lições sobre Ética, segundo a qual as pessoas que por razões egoístas contratualistas entram num sistema de obrigações mútuas não podem ter uma relação afirmativa para a sua consciência, pois, neste caso, se pressupõe que a pessoa que uma vez se encontre num sistema moral não pode ter outras motivações que não aquelas que foram as razões para entrar nele. Parece-lhe, contudo, não ser assim, pois, uma vez dentro de um sistema moral, o mesmo gera, por sua vez, outra motivação. 
Segundo o autor, aquele que entra em um sistema moral prefere que as pessoas tenham uma consciência moral, pois, só assim, elas podem ser confiáveis. E, como a moral é uma coisa recíproca, não se pode dizer que só os outros devam ter uma tal consciência.

Um outro aspecto em relação ao qual o autor revê a sua posição anterior é quanto à idéia de que a moral contratualista não pode ser uma verdadeira moral pelo fato do contrato ser uma coisa que se negocia e onde se chega a um acordo somente quando o que é bom para uma parte é bom para a outra. Ficaríamos aqui apenas com as caracterizações: bom para $a$ e bom para $b$ e, desta forma, não chegaríamos ao predicado geral de bom, sem o qual não teríamos uma moral. Ele atualmente pensa, entretanto, que a consciência pressupõe um conceito de bom, pois, se não o temos, não podemos falar de uma avaliação mútua. Uma relação mútua pressupõe a constituição de um nós. Tugendhat faz questão, neste ponto, de ressaltar a distinção entre contrato moral e contrato comum. Porque no contrato moral os participantes não são negociadores, senão que cada qual decide tomar parte numa sociedade moral com um predicado comum bom. $\mathrm{O}$ autor estabelece, então, no mesmo sentido, a diferença entre contratualismo moral, que ele julga correto, do contratualismo vulgar, que é representado por David Gauthier. Pois, argumenta o autor, no contratualismo moral junto ao conceito de bom gerase 0 conceito de justo. Enquanto que o contratualismo vulgar não pode explicar a geração deste último conceito. Ele acrescenta que o significativo do conceito de justo é que não tem conceitos subjetivos correspondentes ao conceito de bom para x e bom para y. Não se pode dizer justo para $x$, porque a avaliação de justo se refere ao equilíbrio entre as diferentes pessoas. Uma moral que não contém o conceito de justo não é possível porque a moral é um sistema de obrigações mútuas, tem que ser justificável mutuamente e a justiça se refere ao equilíbrio desta mutuabilidade.

A partir deste eixo argumentativo Tugendhat afirma que o contratualismo poderia ser ao menos o núcleo de uma moral não autoritária. Quais poderiam ser, então, os outros componentes da moral. É neste ponto de seu raciocínio que se refere à possibilidade da incorporação do altruísmo espontâneo a este núcleo de moral contratualista. Pois o autor considera que o altruísmo espontâneo não só é um dado como também, provavelmente, fundado biologicamente. E, observa: sem tendências altruístas a espécie não teria sobrevivido. Ele recusa, no entanto, uma moral baseada somente nos sentimentos como os de compaixão e simpatia. Para o autor, a virtude do contratualismo consiste em nem pressupor uma crença transcendente, nem uma valoração especial imanente. Afirma, ainda, que o contratualismo surgiu primeiro no ocidente porque aí primeiramente se perdeu, antes que em outras culturas, a fé tradicionalista.

Tugendhat argumenta, por fim, que uma vez que o mecanismo da moral já está funcionando na base contratualista 0 altruísmo espontâneo poderia suplementá-lo. O que, para ele, parece não só uma possibilidade mas a realidade de nossa consciência moral. Desta forma, a idéia do altruísmo espontâneo não somente tem um lugar no sistema contratualista como pode ser reforçada por ele. Pois, se o altruísmo espontâneo não serve para pôr em movimento o sistema de obrigações mútuas pode, no entanto, constituir-se num complemento do contratualismo moral. 
O confronto entre as posições assumidas por Tugendhat, em relação ao contratualismo moral, permite-nos situarmos o local da "virada" contratualista que ocorre em sua Ética. A lógica de seu raciocínio revela alguns passos decisivos. A recusa a uma moral tradicionalista, assim como a moral kantiana, remonta à sua obra Lições sobre Ética, quando o autor argumenta que um eu tenho de não baseado em um eu quero, sempre implícito, é um absurdo. Nesta obra, contudo, o autor considera o contratualismo uma moral insuficiente ou, nas suas próprias palavras, uma "quase moral". Dois aspectos, ao meu ver, serão determinantes para adesão posterior de Tugendhat ao contratualismo. Primeiro, sua recusa ao sentido do contrato moral enquanto negociação, posição esta assumida pelo que ele denomina contratualismo vulgar, da qual D. Gauthier apresenta-se como representante, passando, então o autor, a compreender a idéia do contrato enquanto justificação, ou seja, a idéia de algo que possa ser justificado para o individuo, no sentido de que o indivíduo possa aceitá-lo ou não. Em outros termos, não como na moral tradicionalista porque Deus quer ou em Kant porque a razão impõe, mas "porque eu quero e porque eu quero deve ser justificada". O contrato moral simbolizaria, assim, aceitação voluntária coletiva. O contrato, desta forma, só se legitima na medida em que há não simplesmente um interesse instrumental de eu respeitar para ser respeitado, mas de se viver uma realidade que supere o valor meramente relativo do bom - bom para $a$ e bom para $b$-porém, uma realidade em que os membros da comunidade procuram participar de uma sociedade boa no geral porque também justa.

Segundo, a partir desta alteração do sentido do contrato moral, que permite o contratualismo tornar-se o "núcleo de uma moral não autoritária", o autor reivindica a incorporação a este núcleo do altruísmo espontâneo, que, no seu entender, encontra-se fundado no homem biologicamente, em seus sentimentos, mas que pode ou não ser desenvolvido. E, assim, o contratualismo moral constituir-se-ia no terreno ideal para o florescimento do altruísmo espontâneo que poderia suplementá-lo coerentemente. Finalmente, para Tugendhat, o contratualismo, assim compreendido, constitui-se numa concepção igualitarista e universal conduzindo a uma autonomia comum. Nestes termos, "a base da moral moderna só pode ser entendida como contratualista" (Anpof, 1998, p. 271).

\section{Referências bibliográficas}

TUGENDHAT, Ernst. Lições sobre Ética. Petrópolis: Vozes, 1997. GAUTHIER, David. Morals by agreement. Oxford: Clarendon Press, 1986.

ANPOF. Livro de resumos. Caxambu, 1998. 